\title{
A percepção dos alunos com deficiência sobre a sua inclusão nas aulas de Educação Física escolar: um estudo de caso
}

CDD. 20.ed. 796.017

796.019

http://dx.doi.org/10.1590/1807-55092014000200329
Maria Luiza Tanure ALVES ${ }^{*}$

Edison DUARTE*
*Faculdade de Educação Física, Universidade Estadual de Campinas.

\section{Resumo}

0 estudo tem como objetivo investigar a inclusão a partir da perspectiva do aluno com deficiência dentro do contexto das aulas de educação física escolar. Participaram do estudo três estudantes entre 12 e 21 anos com deficiência física ou visual do sexo feminino. Foram aplicadas entrevistas semi-estruturadas com roteiro pré-definido e anotações de campo como instrumentos de medida. A inclusão no contexto das aulas de educação física esteve vinculada a três fatores: adaptação, participação social e capacidade. Estes fatores agiram de forma dependente e complementar para a construção de um senso de pertencimento, aceitação e valor dentro do grupo.

Palavras-chave: Aluno com deficiência; Processo inclusivo; Educação física escolar.

\section{Introdução}

O termo inclusão está associado com o atendimento educacional para garantir que todos os alunos, independente de suas capacidades, alcancem todo seu potencial em local escolar apropriado ${ }^{1-4}$. $\mathrm{O}$ aluno com deficiência deve frequentar o sistema regular de ensino junto com seus pares sem deficiência, se beneficiando com educação de qualidade, e reestruturaçáo escolar para atendimento das suas necessidades educacionais. A inclusão educacional é um direito garantido pela legislação educacional vigente $e^{5-10}$.

Apesar dos diferentes conceitos de inclusão descritos no campo da educação física adaptada ${ }^{1-3}$, o presente estudo partiu da ideia que a inclusão deve ser compreendida como uma experiência subjetiva, a qual está associada com interpretaçôes, sentimentos, crenças e percepçóes individuais ${ }^{11}$. Para StaInbaCK e STAINBACK ${ }^{12}$ a experiência de sentir-se incluído está vinculada a estruturação de um senso coeso de comunidade, aceitação das diferenças e resposta às necessidades individuais. A comunidade escolar envolve a participação e a responsabilidade de todos para o alcance de objetivos comuns. Neste ponto a comunidade escolar tem em seus princípios a valorização da diversidade entre seus membros, onde cada um tem seu papel, desempenhando atividades de acordo com seus talentos, potenciais e capacidades.
A comunidade escolar busca, através do trabalho e comprometimento conjunto, o crescimento e desenvolvimento do grupo, com atendimento as necessidades educacionais de todos e a educaçáo de qualidade.

O desenvolvimento da comunidade escolar com a participação de todos, inclusive do aluno com deficiência, permite a estruturaçáo de um senso de pertencimento ao grupo, através da sua importância e valorização no mesmo. Neste contexto, o aluno com deficiência desempenha papéis e funções importantes no grupo, favorecendo o desenvolvimento da percepçáo de pertencimento ao grupo, fundamental para a experiência de sentir-se incluído ${ }^{12}$. A compreensão de inclusão defendida por STAINBACK e STAINBACK ${ }^{12}$ vinculada à necessidade de estruturação de um senso de pertencimento ao grupo será utilizada como base teórica neste estudo, permitindo a sua investigação nas aulas de educação física através das percepções subjetivas dos participantes do estudo. A compreensão de inclusão como experiência subjetiva exige a sua investigação a partir da perspectiva do aluno com deficiência ${ }^{11}$.

Apesar do crescimento nas pesquisas realizadas sobre inclusão na última década, estas ainda se mostram reduzidas. BLOCK е ОвRUSNIKOVA ${ }^{13}$ analisaram um período de 10 anos (1995-2005) de pesquisas publicadas no campo da inclusão nas aulas educação 
física. Entre os 38 trabalhos analisados, apenas um reduzido número de estudos ${ }^{14-18}$ tinham como foco nas percepçóes do aluno com deficiência.

O objetivo principal deste estudo é investigar a inclusão a partir da perspectiva do aluno com deficiência dentro do contexto das aulas de educação física escolar. Desta forma, o estudo tem caráter qualitativo, com natureza exploratória, descritiva e analítica. O conhecimento das perspectivas do aluno com deficiência permite melhor compreensão do processo de inclusão do mesmo nas aulas de educação física de acordo com o conceito empregado por Stainback e STAINBack ${ }^{12}$; a contribuição para este importante campo de pesquisa; bem como possível conhecimento dos fatores associados com a percepção de sentir-se incluído nas aulas de educação física. O conhecimento das percepçóes do aluno com deficiência possibilita ao professor responder melhor as necessidades de seus alunos, bem como aumentar o senso de pertencimento nas aulas de educação física ${ }^{19}$.

As pesquisas realizadas com foco nas perspectivas do aluno com deficiência tem mostrado a importância das interações sociais para a inclusão nas aulas de educação física ${ }^{11,15,17-18}$. Em estudo realizado com alunos com deficiência física (oito a 12 anos de idade), Spencer-Cavaliere e Watkinson ${ }^{11}$, identificaram três temas principais relacionados com a inclusão em ambientes de prática de atividade física (esportes e jogos). Apesar de não ter como foco as aulas de educação física escolar, o estudo demonstra que a percepção de inclusão estava vinculada às oportunidades de participar do jogo, sentir-se como um participante legítimo, bem como ter relações de amizade dentro do grupo. As experiências positivas ou negativas de inclusão estavam associadas com a ocorrência ou não de interação social com os colegas.

Já no contexto específico das aulas de educação física, HutZler et al. ${ }^{18}$ também reportam a importância das interaçôes sociais para a inclusão do aluno com deficiência. Os autores realizaram estudo sobre experiências de alunos com deficiência física (nove a 15 anos de idade) nas aulas de educaçáo física para identificar os fatores colaboradores e limitantes para inclusão e "empowerment". As experiências de inclusão e "empowerment" estavam relacionadas com o tipo de interação social vivenciadas, onde estas podem propiciar ou limitar a inclusão do aluno com deficiência nas aulas de educação física. As relaçôes sociais que tinham caráter de suporte e aceitação social eram capazes de promover a inclusão enquanto que relaçôes sociais onde estes eram ridicularizados ou ignorados causavam a exclusão do aluno com deficiência.
Em estudo realizado por Goodwin e WATKIN$\operatorname{sON}^{15}$ a inclusão nas aulas de educação física estava associada com experiências positivas e negativas. Os autores realizaram estudo sobre o significado de uma educação física inclusiva para alunos com deficiência física entre 10 e 12 anos. A participação nas aulas de educaçáo física estava relacionada a "dias bons" e "dias ruins". Os "dias bons" estavam associados com experiências que proporcionavam senso de pertencimento, chance de se beneficiar com o programa de atividades, e oportunidade de participar nas atividades junto com seus colegas de classe. $\mathrm{O}$ senso de pertencimento ao grupo tinha origem no suporte recebido pelos colegas e professores durante as aulas de educação física. Por sua vez, a participaçáo ativa nas atividades da aula permitia que $o$ aluno com deficiência se beneficiasse dos objetivos do programa, bem como tivesse oportunidade para demonstrar eficiência e estabelecer relaçóes sociais com os colegas de classe ${ }^{15}$.

Entretanto, nos "dias ruins" os alunos com deficiência vivenciavam isolamento social, sentiamse diferentes devido à deficiência, ou tinham participação limitada nas atividades. $\mathrm{O}$ isolamento social estava associado com rejeição, negligencia ou ser alvo de curiosidade pelos colegas de classe. Os alunos também tinham sua capacidade de execução das atividades questionada pelos colegas ${ }^{15}$.

O isolamento social também foi identificado por Place e Hodge ${ }^{17}$ em seu estudo sobre as relações sociais estruturadas pela criança com deficiência nas aulas de educação física escolar. Place e Hodge ${ }^{17}$ descrevem que as interaçóes entre essas e seus colegas sem deficiência acontecem de forma reduzida, devido principalmente à distância espacial existente entre as partes, visto que o grupo de alunos com deficiência encontrava dificuldades para chegar ao local de aula. Os alunos com deficiência demonstravam sentimentos de exclusão devido a comportamentos de rejeição, ser visto como alvo de curiosidade, e ainda por sentir-se incomodado durante as interaçôes sociais com os colegas de classe.

Os estudos citados demonstram que o aluno com deficiência ainda não se sente totalmente incluído nas aulas de educação física. A inclusão deste aluno é dependente da qualidade das interaçóes sociais estruturadas, onde estas devem ser positivas e permitir que o mesmo se sinta aceito, reconhecido por sua capacidade de desempenhar um papel importante no grupo. Esta necessidade reforça a relaçáo existente com a compreensão de inclusão defendida por STAINBACK e STAINBACK ${ }^{12}$ como um senso de pertencimento, aceitação e importância dentro do seu grupo social. 
Este olhar possibilita aos professores de educação física a compreensão da ideia de inclusão como uma experiência subjetiva e única para o aluno. No entanto, a sua concretização está intimamente associada com as experiências vivenciadas durante as aulas de educação física, onde estas devem proporcionar um senso de pertencimento ao grupo, com valorização das suas potencialidades e capacidades frente ao grupo. Desta forma, a investigação da inclusão de alunos com deficiência deve ter como foco central as perspectivas e percepçóes do próprio aluno com deficiência, permitindo a compreensão dos fatores positivos e negativos presentes neste processo.

\section{Método}

O estudo tem foco na perspectiva subjetiva do participante, com caráter de estudo de caso qualitativo, design exploratório, descritivo e analítico.

\section{Participantes}

O estudo contou com a participação de três estudantes (P1, P2 e P3) do sexo feminino (QUADRO 1) de uma escola pública no município de São Paulo - SP. Como critérios de inclusão no estudo os participantes com deficiência visual deveriam: 1) estar matriculadas em escola do sistema regular de ensino entre a $5^{\mathrm{a}}$ série do ensino fundamental e o $3^{\circ}$ ano do ensino médio; 2) apresentar frequência de no mínimo $75 \%$ nas aulas de educação física; e 3) não apresentar dispensa médica para participaçáo nas aulas de educaçáo física. Foram excluídos do estudo os alunos que apresentaram dificuldades ou outras deficiências associadas que os impediam de ser expressar verbalmente durante as entrevistas. $\mathrm{O}$ estudo foi submetido e aprovado pelo Comitê de Ética da Universidade Estadual de Campinas - UNICAMP com o protocolo número 311/2011.

QUADRO 1-Descrição dos participantes do estudo.

\begin{tabular}{|l|c|c|c|c|c|}
\hline Pseudônimo & Sexo & Idade & Série & Deficiência & Locomoçáo \\
\hline P1 & Feminino & 12 & 7a/Ensino fundamental & Paralisia Cerebral & Cadeira de rodas \\
\hline P2 & Feminino & 17 & $2^{\text {o ano/Ensino médio }}$ & Dermato polimiosite & Cadeira de rodas \\
\hline P3 & Feminino & 21 & $3^{\circ}$ ano/Ensino médio & Baixa visão & $\begin{array}{c}\text { Independente com uso } \\
\text { de bengala }\end{array}$ \\
\hline
\end{tabular}

\section{Coleta de dados}

O estudo utilizou entrevistas semi-estruturadas e anotaçôes de campo como instrumentos de medida. As entrevistas semi-estruturadas têm como objetivo acessar a perspectiva do entrevistado, fazendo com que a pessoa reconstrua a sua experiência de acordo com o tópico estudado ${ }^{20-21}$.

Como forma de criar um ambiente amistoso entre pesquisador e entrevistado, inicialmente foi realizada uma conversa sobre os interesses e atividades do entrevistado na escola. As entrevistas seguiram um roteiro pré-estruturado com questóes abertas (QUADRO 2). Este tipo de estrutura permite que o pesquisador explore os conceitos de interesse do estudo, bem como, tenha flexibilidade para aprofundar nas respostas dadas pelos participantes ${ }^{21}$.

$\mathrm{O}$ roteiro de entrevista empregado utiliza a mesma técnica descrita por WatKinson et al. ${ }^{22}$.
Nesta técnica o entrevistado é questionado sobre as perspectivas de outra pessoa nas mesmas condiçóes que ele, para posteriormente responder sobre suas próprias perspectivas. Ao responder inicialmente sobre uma pessoa fictícia nas suas mesmas condiçôes, o entrevistado náo tem de expor seus sentimentos e sensaçóes logo no começo da entrevista ${ }^{22}$. Tais entrevistas foram realizadas individualmente pelo próprio pesquisador em horário pré-estabelecido, em comum acordo com o entrevistado, com registro na forma de gravação direta (formato de MP3 com uso de gravador de voz modelo RR-US511 da marca Panasonic).

As anotaçóes de campo têm como objetivo principal registrar as informações relevantes decorrentes da entrevista que possa auxiliar no processo de análise dos dados posterior. Para tanto, foram registrados os dados pessoais, data, local, bem como as impressóes pessoais do pesquisador sobre a entrevista. 
QUADRO 2 - Roteiro de entrevista.

\begin{tabular}{|c|c|}
\hline Questão 1: & O que significa pra você estar incluído? \\
\hline Questâo 2: & $\begin{array}{l}\text { Que tipo de coisa pode fazer uma outra criança como você se sentir mais incluída na aula de educação } \\
\text { fisica? }\end{array}$ \\
\hline Questáo 3: & $\begin{array}{l}\text { Que tipo de coisa pode fazer uma outra criança como você se sentir menos incluida na aula de } \\
\text { educaçáo física? }\end{array}$ \\
\hline Questão 4: & $\begin{array}{l}\text { Você pode me dar um exemplo de quando uma criança como você se sente mais incluída na aula de } \\
\text { educaçáo física? }\end{array}$ \\
\hline Questáo 5: & $\begin{array}{l}\text { Você pode me dar um exemplo de quando uma criança como você se sente menos incluida na aula de } \\
\text { educaçáo física? } \\
\text { Agora vamos falar de você. }\end{array}$ \\
\hline Questão 6: & Como você se sente durante as aulas de educação física? \\
\hline Questão 7: & O que acontece nas aulas de educação física que faz você se sentir mais incluida? \\
\hline Questáo 8: & O que acontece nas aulas de educação física que faz você se sentir menos incluida? \\
\hline Questão 9: & $\begin{array}{l}\text { Você pode me dar um exemplo de alguma coisa que acontece na sua aula de educaçáo física que faz } \\
\text { você se sentir incluida? }\end{array}$ \\
\hline Questão 10: & $\begin{array}{l}\text { Você pode me dar um exemplo de alguma coisa que acontece na sua aula de educaçáo física que faz } \\
\text { você se sentir menos incluida? }\end{array}$ \\
\hline
\end{tabular}

\section{Análise dos resultados}

Todas as entrevistas foram transcritas verbalmente na íntegra, respeitando-se as características linguísticas de cada participante. As entrevistas semiestruturadas foram analisadas através da análise de conteúdo, utilizando a técnica de análise categorial descrita por BARDIN ${ }^{23}$. A análise categorial se utiliza principalmente da análise temática, que, por sua vez, "consiste em descobrir os núcleos de sentido que compóem a comunicação e cuja presença ou frequência de aparição pode significar algo para o objetivo analítico escolhido"23 (p.131).

Neste tipo de análise há o desmembramento do texto (entrevistas) em unidades de registro, que consistem em unidades de significação do texto e podem ser de dimensóes e natureza variáveis, podendo ser frases, palavras ou expressóes. Estas devem carregar em si os pontos-chave de significação para o sujeito a respeito da experiência estudada. As unidades de registro revelam ao pesquisador o significado e sentido do ponto estudado. As unidades de registro são reagrupadas posteriormente em categorias temáticas por semelhança ${ }^{23}$.

Posteriormente, os temas emergentes de cada entrevista são categorizados em grupos temáticos maiores considerando-se o conjunto das entrevistas realizadas. Nesta etapa busca-se a transversalidade temática, ou seja, busca por temas que permeiam o conjunto das entrevistas realizadas. Após essa categorização é realizado o processo de inferência e interpretação das categorias temáticas presente no conjunto dos discursos (entrevistas) permitindo a análise e compreensão dos significados latentes. Dessa forma, as entrevistas são analisadas e interpretadas dentro de sua singularidade, bem como na sua coletividade ${ }^{23}$.

As observaçôes realizadas no diário de campo foram organizadas em forma de relatórios. Estes tinham como objetivo ao pesquisador fornecer dados relevantes sobre a entrevista, como data, local, acontecimentos importantes durante a entrevista, e observaçôes a serem consideradas durante a análise dos dados.

\section{Resultados}

Os resultados serão descritos a partir das palavras dos próprios participantes. Cada entrevista teve duração média de 32 minutos, resultando em um total de 23 páginas de transcrição verbal. Os participantes demonstraram boa compreensão das questôes formuladas. 
Para os participantes do estudo, a inclusão no contexto das aulas de educação física está vinculada a três fatores essenciais: adaptação, participação social e capacidade. Todos os fatores foram mencionados por todos os participantes, atuando de forma complementar para a percepção de inclusão do aluno com deficiência.

\section{Adaptação}

Um dos fatores críticos para a inclusão do aluno com deficiência nas aulas de educação física é a adequação deste contexto para o atendimento às suas necessidades. Para os participantes do estudo, esta adequação é constituída pela adaptação estrutural, pedagógica, metodológica e material para participação ativa na aula. Estas adaptações devem ocorrer de acordo com a necessidade, limitaçóes e capacidades do aluno com deficiência.

Para adaptação das aulas é fundamental a capacitação do profissional de educação física, bem como da unidade escolar para o recebimento do aluno com deficiência. Este ponto fica claro na fala da P1 "Porque eu conheço vários amigos que não estudam, tem a mesma idade que eu e ele num consegue ir pra escola por causa que os professores num tão preparados e as escolas também não". Neste ponto observa-se que a responsabilidade de inclusão do aluno com deficiência náo é exclusiva do professor, mas da unidade escolar como um todo.

A adaptação das aulas de educação física deve permitir ao aluno com deficiência a sua aprendizagem e participação nas atividades. Ao ser questionada sobre o que pode ser feito para possibilitar a inclusão de outro aluno como ela, a P2 expóe esta necessidade de aprendizagem dos conteúdos ao dizer "Aprender várias coisas diferentes, né? Jogar várias coisas diferentes durante a aula” (P2). No entanto, para que a aprendizagem ocorra é fundamental que o professor adapte sua metodologia de ensino para atender as necessidades de seu aluno com deficiência. Já a P1 expressa esta necessidade ao dizer "[...] por mais que a gente tenha dificuldade, o professor tá ali pra explicar”.

A participação nas mesmas atividades que seus colegas de classe proporcionam ao aluno com deficiência o sentimento de pertencimento ao grupo, como pode ser visto na seguinte fala da P1 "eu participo de quase todas as atividades. Eu me sinto mais incluída quando a professora faz pra eu fazer mais parte da aula”. A P2 ainda completa a ideia dizendo que se sentiria mais incluída quando "puder participar de tudo um pouco. Poder fazer de tudo um pouco. [...] Participando de tudo” (P2).
No caso da P3 (aluna com deficiência visual), a professora utiliza o suporte para garantir a sua participação durante as atividades. Neste caso, os colegas de classe ou o próprio professor atuariam como tutores da aluna com deficiência visual. Para esta participante, esta forma de adaptação permite a execução das atividades junto com seus colegas de classe, propiciando a percepção de inclusão na aula. A P3 descreve a sua participação através de tutoria ao dizer "Porque teve um dia aí que eu não queria fazer esse circuito aí. Aí ela pegou, pegou na minha mão e "vai, vamos passar por todo o circuito.." Aí, acabei fazendo...mas se ela não tivesse vindo, eu acho que eu não teria feito".

A tutoria pode ser exercida pelo professor de educação física, mas também pode ser executada pelos próprios colegas de classe. Para a P3 a tutoria é um dos fatores de maior influência na sua percepção de inclusão como pode ser observado na fala "Se você acha que num consegue fazer alguma coisa, o seu professor vai lá e faz junto com você e te mostra que você consegue. Seus amigos também. Então, é a ajuda deles e o meu esforço" (P3).

Os materiais utilizados aparecem como outro ponto fundamental a ser adaptado nas aulas de educação física. Quando questionada sobre o que faltaria para que se sinta incluída, a P3 diz "Ah... eu acho que falta adaptação de material, né? Por exemplo, se tivesse uma bola com guizo. Talvez eu pudesse jogar futebol ou pudesse jogar volei, porque eu ia tá ouvindo quando ela vinhesse, né?”, sugerindo a importância desse tipo de adaptação para sua participação ativa nas atividades da aula. Para a participante, sua participação nas aulas de educação física é limitada devido à ausência de materiais adaptados para tal.

A adaptação nos materiais da aula deve possibilitar o desenvolvimento das potencialidades do aluno com deficiência. A P3 ao dizer "[...] eu consigo ver cores com alto contraste, assim, sabe? Se tivesse uma dama (jogo de tabuleiro) com peças que tivesse cores diferentes, tal... talvez eu conseguisse jogar também”, sugere a possibilidade de participação nas atividades da aula de educação física através do seu resquício visual. Para a participante, a adaptação de materiais da aula de educação física possibilita a participação ativa nas atividades, e como consequência a sua percepção positiva de inclusão.

A adaptação estrutural do espaço da aula de educação física também é descrita como fundamental para a percepção de inclusão pelo aluno com deficiência. Para a P2, a sua inclusão realmente 
ocorre quando ela "circular melhor pelos cantos", indicando a sua necessidade de acessibilidade aos espaços utilizados. Para esta participante (P2), os espaços utilizados na aula de educação física não permitem a sua locomoção independente e autônoma, restringindo sua participação nas atividades de aula, bem como sua participação social com seus colegas de classe.

\section{Participação social}

A participação social nas aulas de educação física aparece como ponto crítico e fundamental para a percepção de inclusão. Este aspecto foi mencionado por todas as participantes do estudo. A participação social refere-se à convivência do aluno com deficiência com seus pares na escola. Este aspecto está associado com dois fatores principais: a aceitação pelo grupo, e a interação social com o grupo ao qual está inserido.

A aceitação consiste na compreensão e aceitação da deficiência pelo seu grupo de colegas. A P2 se sente incluída "quando as pessoas mesmo aceitam". Para a P1, para sentir aceita pelo grupo é necessário a compreensão pelos colegas de classe da sua deficiência, como pode ser visto na sua fala "os professores também...é...explica pros meus colegas que eu tenho uma dificuldade, que eles tem que compreender também". A aceitação social também está associada com a percepção de sentir-se querida pelo grupo, recebendo tratamento semelhante a seus pares. A P1 explica que se sente incluída "Por causa que eles me tratam bem [...] Todos eles gosta de mim".

A questão da aceitação social ainda implica sentir-se aceita para participar das atividades da aula de educação física junto com seus colegas de classe, como pode ser observado na fala da P2 "[...] aceitam eu jogar. Quando táo várias pessoas reunidas assim, aceitam eu jogar, né?”. A P3 completa esta ideia com a passagem "eu sempre tô junto ali com eles, né? [...] Se vão fazer alguma coisa: "ai, vamo lá, vamo fazer também, tal" [...] E não falar "Não, fica aí que eu vou ali fazer um negócio e já volto". Nesta fala a P3 ainda sugere que sentir-se aceita por seus colegas de classe possibilita o sentimento de pertencimento ao grupo, permitindo a percepção de inclusáo.

Para as participantes do estudo a interação social com seus colegas de classe permite que se sintam incluídas. A P2 descreve que irá se sentir incluída quando "começar a se sentir mais no meio de todo mundo, né". Para a P2 a inclusão acontece quando eu consigo chegar mais nas pessoas. Porque eu também sou um pouco tímida. Aí, quando eu consigo chegar mais nas pessoas, sem meio que a ajuda da professora, com outras pessoas que eu num conheço, de outras classes, aí eu me sinto mais incluída lá.

Para a percepção de inclusão as interaçóes sociais devem estar associadas com a atividade da aula. A P1 relata que se sente incluída quando "quando tá os meus colegas todo mundo junto participando da mesma coisa”. Ao descrever o que a faz sentir como parte da turma, a P2 compartilha dessa opinião na fala "Acho que quando a gente tá reunido brincando, sabe? Porque de vez em quando junta quase todo mundo da sala pra brincar de uno".

\section{Capacidade}

A percepção de inclusão em alunos com deficiência nas aulas de educação física também é influenciada pelo sentimento de sentir-se capaz de realizar as atividades da aula. Para a P1 é importante sentir-se como um integrante legítimo da classe, capaz de executar as tarefas exigidas. A P1 descreve esta sensação ao dizer "os professores num dá atenção... tipo, se você copiou, copiou...se você não copiar deixa pra lá...tipo, pensando que você é incapaz de responder algumas coisas" (P1).

A possibilidade de demonstrar suas capacidades e habilidades para os colegas de classe e professores também é indicada como capaz de promover a percepçáo de inclusão em alunos com deficiência. Dentro deste contexto é fundamental que o aluno com deficiência desempenhe papeis e funçóes semelhantes a seus colegas de classe sem deficiência nas atividades de aula. A P1 descreve esta situação ao contar sobre a sua participação em um campeonato na escola

[...] eu participei de um campeonato na outra es-

cola.[...]Foi legal. Eu ate ganhei uma medalha. Me senti bem contente.[...]É..tipo, eu nunca imaginava que eu ia participar de campeonato.

Para a P3 é fundamental realizar as atividades propostas em aula pelo professor. A capacidade de conseguir concluir as atividades promove na participante a sensação de sentir-se como membro do grupo. A P3 relata que realizar as atividades da aula lhe deixa "sempre feliz, porque to conseguindo fazer, assim...Tudo que eu consigo fazer é uma felicidade...é como se eu tivesse vencendo mais um obstáculo". A P3 completa esta ideia ao relatar suas atividades durante as aulas de educação física na seguinte interação com o pesquisador

Pesquisador: Você pode me dar um exemplo de alguma coisa que acontece na sua aula de educação física que faz você se sentir incluída? 
Entrevistado: É quando eu chego, tal...que ela (professora) já vem com a corda também. E aí eu pulo. Eu pulo de vários jeitos, né? Eu cruzo a corda, pulo de costas. Então, ela reconhecendo isso já me faz me sentir mais incluída também.

No trecho ainda podemos observar a importância para o aluno com deficiência do reconhecimento pelos colegas de classe e seu professor das suas capacidades. A percepção pelo aluno com deficiência que esta sendo reconhecido como um membro capaz e importante para a turma promove a percepção de inclusão do mesmo. A relevância de ser reconhecido também foi expressa na fala da P1 mencionada acima onde a mesma relata a felicidade da turma quando a mesma conseguiu ganhar o campeonato de basquete em cadeira de rodas e de damas.

\section{Discussão}

O presente estudo partiu da perspectiva que é necessário analisar a inclusão dos alunos com deficiência em aulas de educação física por meio da percepção dos alunos. A ideia central é que a inclusão necessita ser compreendida como uma experiência única, subjetiva e associada com as crenças, percepçôes e sentimentos do aluno com deficiência. Nesta perspectiva, de acordo com os resultados do estudo, a experiência subjetiva de inclusão das alunas esteve associada a três fatores essenciais: adaptação, participação social e capacidade. Estes fatores agiram de forma complementar e dependente. Vale lembrar que a adaptação refere-se à adequação do contexto (estrutura física, material, método de ensino, conteúdo e objetivos) das aulas de educação física para o atendimento às necessidades do aluno. A necessidade de adaptação das aulas de educação física as capacidades do aluno com deficiência também é descrita por Blinde e McCallister ${ }^{14}$, Block e Obrusnikova ${ }^{13}$, Hutzler et al. ${ }^{18}$, Place e Hodge ${ }^{17}$. O atendimento as necessidades do aluno com deficiência pressupóe formação profissional de qualidade, não apenas para os professores da disciplina, mas para todos os que trabalham na escola. Sentir-se incluído ultrapassa as barreiras da sala de aula, sendo necessário que o aluno tenha atendida e reconhecida suas necessidades em todo o ambiente escolar.

As adaptaçóes necessárias para o aluno com deficiência devem permitir que este consiga sentir-se beneficiado com o processo de ensino-aprendizagem, bem como participe socialmente dentro do seu grupo. Isto permite que o aluno com deficiência estruture o sentimento de pertencimento ao grupo, essencial para se sentir incluído ${ }^{12}$. Pesquisas realizadas por GoodwIN e Watkinson ${ }^{15}$, Spencer-Cavaliere e WatKinson ${ }^{11}$ também apontam a importância do senso de pertencimento para inclusão do aluno com deficiência.

Colaborando com os resultados encontrados, LEONARDo et al. ${ }^{24}$ descrevem que as adaptaçôes realizadas em escolas públicas e privadas brasileiras visando à inclusão de alunos com deficiência restringem-se em grande parte a alteraçóes no espaço físico, sem qualquer tipo de planejamento pedagógico para receber este aluno. Neste campo, a falta de capacitação profissional e infraestrutura escolar são as maiores dificuldades vivenciadas pelos professores para a inclusão. Os professores de educação física afirmam possuir pouco ou nenhum conhecimento sobre os tipos de deficiências dos seus alunos ${ }^{24} \mathrm{e}$ falta de experiência e treinamento inadequado em inclusão ${ }^{2,13,25}$.

No entanto, a falta de preparação profissional não é um problema único da realidade brasileira, visto que os professores de educação física da União Européia se sentem despreparados para o ensino de alunos com deficiência no contexto inclusivo, relatando também a ausência de suporte para tal. De acordo com os padróes assumidos pela Comunidade Europeia, os professores de educação física adaptada devem ser capazes de implementar todas as adaptaçóes necessárias para a inclusão do aluno com deficiência no contexto das aulas de educação física. As competências-chave a serem adquiridas por estes profissionais podem ser divididas em quatro áreas focadas em: 1) preparação; 2) ensino; 3) avaliação e; 4) colaboração e aprendizagem ao longo da vida ${ }^{26}$.

No caso da participante do estudo com deficiência visual, a tutoria funcionou como uma forma de adaptação no método de ensino capaz de suprir suas necessidades. A tutoria permitiu que a aluna participasse das atividades propostas, bem como interagisse com seus colegas de classe. No caso específico da tutoria, esta consiste em um modelo onde colegas de idade próximas dão assistência a colegas com deficiência durante as aulas de educação física $^{13}$. Resultados semelhantes ao aqui descritos foram relatados em estudos onde o uso de tutores treinados foi capaz de aumentar a participação de alunos com deficiência nas aulas de educação física ${ }^{27-28}$. 
A tutoria é reconhecida como um modelo de suporte, o qual se refere a qualquer pessoa que preste assistência ao aluno com deficiência durante as aulas de educação física ${ }^{13}$. Este pode ser realizado por uma variedade de pessoas, porém a literatura sobre o tema indica que são utilizados principalmente os professores assistentes ou professores especialistas em educação física adaptada ${ }^{13}$. O suporte tem um impacto positivo nas experiências durante as aulas de educaçáo física, e ainda previnem efeitos negativos sobre os pares sem deficiência ${ }^{13}$. No entanto, Goodwin ${ }^{16}$ descreve que o tipo de suporte oferecido durante as aulas de educação física pode prejudicar a inclusão dos alunos com deficiência quando impede a independência dos mesmos.

Já em relação às participantes com deficiência física ficou evidente a importância da acessibilidade aos locais da aula de educação física. A falta de autonomia e independência para sua locomoção no ambiente da aula impede a sua participação nas atividades propostas e a interaçáo com os colegas de classe. Estes resultados são semelhantes ao encontrados por Pivik et al. ${ }^{29}$, Place e Hodge ${ }^{17}$. Ambientes escolares inclusivos devem garantir o acesso físico, a oportunidade para a aprendizagem ideal e social, e proporcionar um clima estimulante ${ }^{29}$.

Neste caso a falta de acessibilidade prejudicou o senso de pertencimento ao grupo, impossibilitando com que as mesmas se sentissem incluídas nas aulas de educação física. A ausência de estrutura física adequada é uma realidade vivenciada em toda estrutura escolar, e não apenas no contexto das aulas de educação física ${ }^{29-30}$.

Para as participantes do estudo a participação social durante as aulas de educação física aparece como ponto fundamental para a percepção de inclusão. Esta diz respeito à sentir-se aceita pelo grupo e interagir socialmente no mesmo. A aceitação pelo grupo está presente em situações onde o aluno com deficiência é convidado pelos colegas de classe a participar das atividades propostas em aula, é reconhecido como um membro importante e com seu valor para seu grupo, bem como tem atendida suas necessidades para participação na aula. Neste ponto, o aluno com deficiência deve receber tratamento semelhante aos demais tanto pelo professor da disciplina quanto por seus colegas. Resultados semelhantes foram descritos por GoODWIN e WATKINSON ${ }^{15}$.

O sentimento de aceitação está intimamente associado com a participação nas atividades propostas na aula de educação física. Este é estruturado principalmente a partir da interaçáo social com o grupo durante as atividades de aula. De forma geral, a participação nas atividades de aula junto com seus colegas de classe permite a interação com os colegas de classe, criando situaçóes onde o aluno com deficiência se sentirá aceito como um membro do grupo. As pesquisas realizadas na área descrevem que a interação social com colegas sem deficiência ainda é limitada ${ }^{14,17-18,31}$, podendo levar o aluno com deficiência ao isolamento social ${ }^{15}$. Em consonância com os estudos citados, os resultados aqui descritos indicam que os aspectos sociais da inclusão ainda não proporcionam apenas experiências positivas para o aluno com deficiência ${ }^{13}$, impedindo a estruturação do senso de pertencimento, importância e valor dentro do grupo, essencial para a inclusão dos mesmos.

Outro ponto chave apontado pelas participantes do estudo para a sua percepçáo de inclusão é a oportunidade para demonstrar suas capacidades como um membro legítimo do grupo. Para tanto o aluno com deficiência deve se sentir capaz de executar as tarefas exigidas durante a aula de educação física. Ter sua capacidade questionada pelos pares sem deficiência age como fator prejudicial para a inclusãa ${ }^{15}$. Devem ser proporcionadas ao aluno com deficiência oportunidades de desempenho de papéis e funçóes semelhantes aos seus colegas de classe sem deficiência nas atividades de aula. A demonstração de suas capacidades dentro do contexto da aula de educaçáo física também permite ao aluno com deficiência sentirse como um membro importante e com valor para seu grupo, capaz de contribuir para os objetivos comuns.

A inclusão do aluno com deficiência nas aulas de educação física é consequência da ocorrência de forma íntima e relacionada dos três fatores principais descritos: adaptação, participação social e demonstração de capacidade. Estes agem de forma conjunta para a construção de um senso de pertencimento, importância e valor dentro do grupo, essencial para a percepção de inclusão. As atividades propostas nas aulas de educação física devem ser preparadas de forma a permitir que o aluno com deficiência participe ativamente e interaja com seus pares. A participação nas atividades e consequentemente a interaçáo social aparecem como pontos primordiais para a inclusão, visto que irão proporcionar ao aluno com deficiência oportunidades para demonstraçáo de suas habilidades e capacidades, desempenho de papéis e funçôes importantes dentro do grupo em busca de um objetivo comum, bem como sentir-se aceito pelo grupo.

Apesar de ser capaz de promover a percepçáo de inclusão através da construção de um senso de pertencimento, importância e valor dentro do grupo, a interação social com os colegas de classe pode 
também não permitir que isto ocorra. De acordo com estudo de Goodwin e WATKInson ${ }^{15}$ a percepção de inclusão está associada com o tipo de interação social estruturada. As interaçóes sociais entre o aluno com e sem deficiência marcadas por reaçôes de rejeição, negligência, sentir-se como alvo de curiosidade pelos colegas de classe, ou ter sua capacidade de execução das atividades questionada pelos colegas impedem a percepção de inclusão pelos alunos com deficiência ${ }^{15}$. Desta forma, a qualidade das interaçóes sociais durante as aulas de educação física influenciam o senso de pertencimento, importância e valor dentro grupo, e consequentemente a percepção de inclusão. Estudos realizados por GoodwIn e WATKInson ${ }^{15}$ e Hutzler et al. ${ }^{18}$ descrevem a vivência pelos alunos com deficiência tanto de experiências positivas quanto negativas no contexto das aulas de educação física, enquanto que o estudo de Blinde e McCallister ${ }^{14}$ descrevem a vivência apenas de experiências negativas.

De forma geral a experiência de estar incluído exige a renovação da estrutura escolar. Esta renovação deve buscar a construção de um senso de comunidade entre os integrantes da escola. O papel e responsabilidade de inclusão nas aulas de educação física não se restringe apenas ao professor responsável pela disciplina. De acordo com Stainback e STAInback ${ }^{12}$, a estruturação da comunidade escolar permitiria o atendimento às necessidades educacionais de todos os alunos, a sua participação nas atividades propostas, e como consequência a sua valorização e interação no seu grupo. Os resultados aqui descritos trazem à tona esta necessidade de mudança de perspectiva, onde a inclusão deixa de ser um problema do professor para ser responsabilidade de todos.

\begin{abstract}
Students with disability's perceptions about inclusion in Physical Education classes: a case study

The study aims to investigate the inclusion from the perspective of disabled students within the context of physical education classes. Participants were three female students between 12 and 21 years with physical disabilities or visual. The study used semi-structured interviews with pre-defined schedule and field records as measuring instruments. Inclusion in the context of physical education classes is linked to three key factors: adaptation, social participation and capacity. These factors act dependent and complementary to building a sense of belonging, acceptance and value within the group.
\end{abstract}

KEY WORDS: Student with disability; Inclusive process; Physical education.

\title{
Referências
}

1. De Pauw K, Doll-Tepper G. Toward progressive inclusion and acceptance: myth or tealyth? The inclusion febate and bandwagon fiscourse. Adapt Phys Activ Q.2000;17:135-43.

2. Lieberman LJ, Houston-Wilson C, Kozub FM. Perceived barriers to including xtudents with visual impairments in general physical education. Adapt Phys Activ Q. 2002;19:364-77.

3. Block ME. A teacher's guide to including students with disabilities in general physical education. 3rd ed. Baltimore: Paul H. Brookes; 2007.

4. O’Brien D, Kudlacek M, Howe PD. A contemporary review of english language literature on inclusion of students with disabilities in physical education: a european perspective. Eur J Adapt Phys Act. 2009;2:46-61.

5. Brasil. LDB 9.394, de 20 de dezembro de 1996: Lei de Diretrizes e Bases da Educação Nacional. Diário Oficial da Uniāo, Brasília (1996 dez. 23); Sec.1:27833. [citado 7 nov. 2012]. Disponível em: http://portal.mec.gov.br/arquivos/pdf/ldb.pdf.

6. Brasil. Decreto Lei n. 3298, de 20 de dezembro de 1999. Diário Oficial da União, Brasília (1999 dez. 21); Sec.1:10 1999.

7. Brasil. Diretrizes Nacionais para a Educação Especial na Educação Básica. Brasília: MEC/SEESP; 2001.

8. Brasil Plano Nacional de Educação - PNE. Brasília: INEP; 2001.

9. Brasil. Decreto n. 186, de 9 julho de 2008. Aprova o texto da convenção sobre os direitos das pessoas com deficiência e de seu protocolo facultativo. Diário Oficial da União, Brasília (2008 jul. 10); Sec.1:1.

10. Brasil. Ministério da Educação. Política nacional de educação especial na perspectiva da educação inclusiva. Brasília: MEC/SEESP; 2008. 
11. Spencer-Cavaliere N, Watkinson EJ. Inclusion understood from the perspectives of children with disability. Adapt Phys Activ Q. 2010;27:275-93.

12. Stainback W, Stainback S. Colaboração, rede de apoio e construção de comunidade. In: Stainback W, Stainback S. Inclusão: um guia para educadores. Porto Alegre: Artes Médicas; 1999.

13. Block ME, Obrusnikova I. Inclusion in physical education: a review of literature from 1995-2005. Adapt Phys Activ Q. 2007;24:103-24.

14. Blinde EM, McCallister SG. Listening to te voices of students with physical disabilities. J Phys Educ Recreation Dance. 1998;69:64-8.

15. Goodwin DL, Watkinson EJ. Inclusive physical education from the perspective of students with physical disabilities. Adapt Phys Activ Q. 2000;17:144-63.

16. Goodwin DL. The meaning of help in PE: perceptions of students with physical disabilities. Adapt Phys Activ Q. 2001;18:289-303.

17. Place K, Hodge SR. Social inclusion of students with physical disabilities in general physical education: a behavioral analyses. Adapt Phys Activ Q. 2001;18:389-404.

18. Hutzler Y, Fliess O, Chacham A, Auweele Y. Perspectives of children with disabilities on inclusion and empowerment: supporting and limiting factors. Adapt Phys Activ Q. 2002;19:300-17.

19. James AR, Kellman M, Lieberman L. Perspectives on inclusion from students with disabilities and responsive strategies for teachers. J Phys Educ Recreation Dance. 2011;82:33-54.

20. Seidman I. Interviewing as qualitative research: a guide for researchers in education and the social sciences. 2 nd ed. New York: Teachers College; 1998.

21. Patton MQ. Qualitative research and evaluative methods. 3rd ed. California: Sage; 2002.

22. Watkinson EJ, Dwyer SA, Nielsen AB. Children teorize about reasons for recess engagement: does expectancy-value theory apply? Adapt Phys Activ Q. 2005;22:179-97.

23. Bardin L. Análise de conteúdo. 4a ed. Lisboa: Ediçốes 70; 2010.

24. Leonardo NST, Bray CT, Rossato SPM. Inclusão escolar: um estudo acerca da implantação da proposta em escolas de ensino básico. Rev Bras Educ Espec. 2009;15:289-306.

25. Chandler JP, Greene JL. A statewide survey of adapted physical education service delivery and teacher in-service training. Adapt Phys Activ Q. 1995;15:370-80.

26. Klavina A, Kudlacek M. Physical education for students with special education needs in Europe: findings of the Eusapa project. Eur J Adapt Phys Act. 2011;4:46-62.

27. Houston-Wilson C, Dunn JM, Van Der Mars H, McCubin J. The effect of peer tutors on motor performance in integrated physical education classes. Adapt Phys Activ Q. 1997;14:298-313.

28. Lieberman LJ, Dunn JM, Van Der Mars H, McCubbin J. Peer Tutors' effects on activity levels of deaf students in inclusive elementary physical education. Adapt Phys Activ Q. 2000;17:20-39.

29. Pivik J, McComas J, Laflame M. Barriers and facilitators to inclusive education. Except Child. 2002;69:97-107.

30. Abe PB, Araújo RCT. A participação escolar de alunos com deficiência na percepção de seus professores. Rev Bras Educ Espec. 2010;16:283-96.

31. Ellis DN, Wright M, Cronis T. A description of the instructional and social interactions of students with mental retardation in regular physical educations settings. Educ Train Ment Retard Dev Disabil. 1996;31:235-241.

\section{Agradecimentos}

Ao Conselho Nacional de pesquisa e Desenvolvimento - CNPq ao apoio ao estudo realizado.

ENDEREÇO

Maria Luiza Tanure Alves

Faculdade de Educação Física

Universidade Estadual de Campinas

Av. Érico Veríssimo, 701 - Cidade Universitária 13083-851 - Campinas - SP - BRASIL e-mail: luizatanure@gmail.com
Recebido para publicação: 29/01/2013

Revisado: 30/08/2013

Aceito: 19/05/2014 